\title{
Autopsy as well as Nano-technological Study of a Suicide by Firearm
}

\author{
Manoj K. Pathak ${ }^{1 *}$, Srishti Rai ${ }^{2}$ \\ ${ }^{1}$ Professor and Former Head, Forensic Medicine, Department of Forensic Medicine, Institute of Medical Sciences, Banaras Hindu \\ University, Varanasi, Uttar Pradesh, India \\ 2Juniour Research Fellow, Forensic Medicine, Department of Forensic Medicine, Institute of Medical Sciences, Banaras Hindu \\ University, Varanasi, Uttar Pradesh, India
}

\section{Abstract further information and said they had no idea why he committed suicide. on the manufacturing and sales of such firearms. \\ Keywords: Contact Shot, GSR, SEM-EDXA, Suicide, WHO. \\ Int J Eth Trauma Victimology (2020). DOI: 10.18099/ijetv.v6i02.10}

Background: The case brought to the department was of a 34 years old man, he had a history of alcohol and drug abuse. He had shot himself in the forehead with an unlicensed locally made firearm. The family members were reluctant in giving any

Case Report: A thorough post-mortem examination was conducted in the Mortuary of the Department of Forensic Medicine, Institute of Medical Sciences, Banaras Hindu University (IMS BHU). Ballistic findings as well as gunshot residue (GSR), were collected to support the claim of suicide. SEM-EDXA was performed on the collected hand swab.

Conclusion: It is important to state the manner of death, in any case, to provide justice to the deceased and hold the indictable person accountable. To prevent such suicides by the use of improvised firearms, strict and stringent laws should be formulated

\section{INTRODUCTION}

A ccording to the World Health Statistics 2019 published by World Health Organization (WHO), India's suicide rate stood at 17.8 suicides per $1,00,000$ people in 2016, much higher than the global suicide rate of 10.5. ${ }^{1}$ About 800,000 people die by suicide worldwide every year, of these, 135,000 $(17 \%)$ are residents of India, a nation with $17.5 \%$ of the world's population. ${ }^{2}$ Suicide is the third leading cause of death in the 15-19 years of age group.

A total of $79 \%$ of global suicides occur in low- and middleincome countries. Ingestion of pesticides i.e., poisoning, hanging and firearms are among the most common methods of suicide globally. ${ }^{3}$ Whoever attempts to commit suicide and does any act towards the commission of such offence, shall he punished with simple imprisonment for a term which may extend to one year 1 [or with fine, or with both]. ${ }^{4}$ Although section 309 is still in effect, the Mental Healthcare Act, April 2017 (enacted July 2018) has restricted its application. The relevant provision of the new act states: Notwithstanding anything contained in section 309 of the Indian Penal Code, any person who attempts to commit suicide shall be presumed, unless proved otherwise, to have severe stress and shall not be tried and punished under the said Code. ${ }^{5}$

A study published by Sachil Kumar et al. In 2013 Out of 5204 suicides were reported in January 2008 to October 2012. A total of $16 \%$ of males and $3 \%$ of females preferred firearm for committing suicide. ${ }^{6}$

In a study reported by Anik Kohli in 2006 in the Delhi region, of the seven suicidal victims, six were males. Of these,
Corresponding Author: Manoj Pathak, Professor and Former Head, Forensic Medicine, Institute of Medical Sciences, Banaras Hindu University, Varanasi-221005, India, e-mail: drmanojpathak@ gmail.com

How to cite this article: Pathak, M.K., \& Rai, S. Autopsy as well as Nano-technological Study of a Suicide by Firearm. Int J Eth Trauma Victimology 2020;6(2):39-43.

Source of support: The present study was funded by University Grants Commission.

Conflict of interest: None

Received:07/09/2020;

Accepted:04/12/2020;

Received in revised form: 30/11/2020; Published:25/12/2020

four were in the age group of 20-30 years, and two were in the age group of 40-50 years. The wounds in all the suicidal cases were contact wounds. ${ }^{7}$

Three methods-hanging, pesticide suicide, and firearm suicide-dominate country-specific suicide patterns. This indicates that hanging is the most preferred method of suicide as it causes painless death when no other major method is available. The proportion of hangings typically decreases as either pesticide suicide or firearm suicide increases. Readily available poisons like opium compounds and barbiturates (cause painless death) and firearms facilitate unplanned suicide acts, which are typical of impulsive suicide. This probably explains why the proportion of firearm suicides in individuals with severe mental illness background is distinctly below average. ${ }^{8}$ In India, there has beenthe rapid proliferation of illegal firearms with a sharp increase in firearm fatalities, especially in Bihar, Jharkhand, and Uttar Pradesh. ${ }^{9}$ 
Proving a gunshot fatality's manner of death is an important aspect of medico-legal investigation. It is common to portray a homicide as a suicide to fool the law enforcement agencies and escape the harsh punishment. It becomes crucial in such suicide cases to prove that they indeed were suicides and no foul play is involved. To determine the manner, a well-coordinated collaboration between the police officials who had visited the crime scene, the medico-legal expert and ballistic experts' opinion is paramount.

Here in this case study we are presenting a typical example of suicidal gunshot fatality. The medico-legal evidences and ballistic evidences point towards the manner of death with complete clarity.

\section{Material and Methods}

The case was brought to the Department of Forensic Medicine, Institute of Medical Sciences, Banaras Hindu University. Post-mortem findings including gross analysis was diligently explored as well as samples of GSR were collected in the Department's mortuary. The gunshot residues were collected from the site of entrance of the bullet as well as from the hands of the victim.

Separate cotton balls dipped in dilute hydrochloric acid were used to swab the area around wound and palm of right hand. The swabs were air-dried and placed in separate, sterile and labeled containers. The swabs were then sent to the Department of Chemical Engineering Indian Institute of Technology, Banaras Hindu University, Varanasi for SEM-EDXA. The analysis is both qualitative and semiquantitative.

\section{RESUlT}

\section{Autopsy Findings}

\section{External examination}

On external examination of the wound, a stellate-shaped or cruciate-shaped entrance wound in the forehead's frontal region and in the mid-line, $7 \mathrm{~cm}$ above the glabella, is present in the deceased as depicted in Figure 1.

The diameter of the circular entrance wound is $1.2 \mathrm{~cm}$.

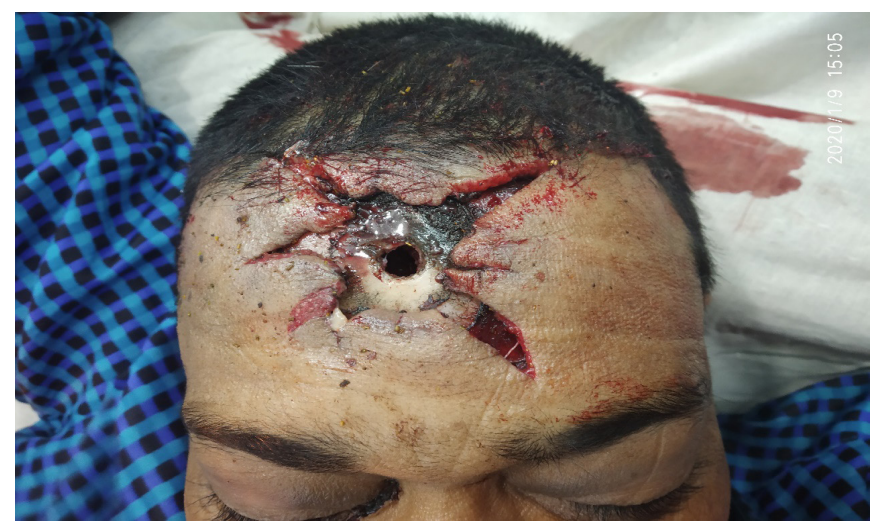

Figure 1: Stellate shaped contact shot wound with scorching effect.
The cruciate wound dimension is diagonally $11 \mathrm{~cm}$ in length, and vertically, it is $3.8 \mathrm{~cm}$, and horizontally, the length of a wound is $5.4 \mathrm{~cm}$ in length.

As it is contact shot due to blast effect, everything, i.e., burning, blackening, and tattooing, which are characteristic features of the entrance wound, went inside the track.

The exit is of $0.7 \mathrm{~cm}$ in diameter and is present in the occipital region. It is $3.5 \mathrm{~cm}$ below the occipital protuberance and $10 \mathrm{~cm}$ outer to right ear. This exit wound is smaller than the entrance wound and this is a typical example of a contact shot where the blast effect exit wound is smaller than an entrance wound.

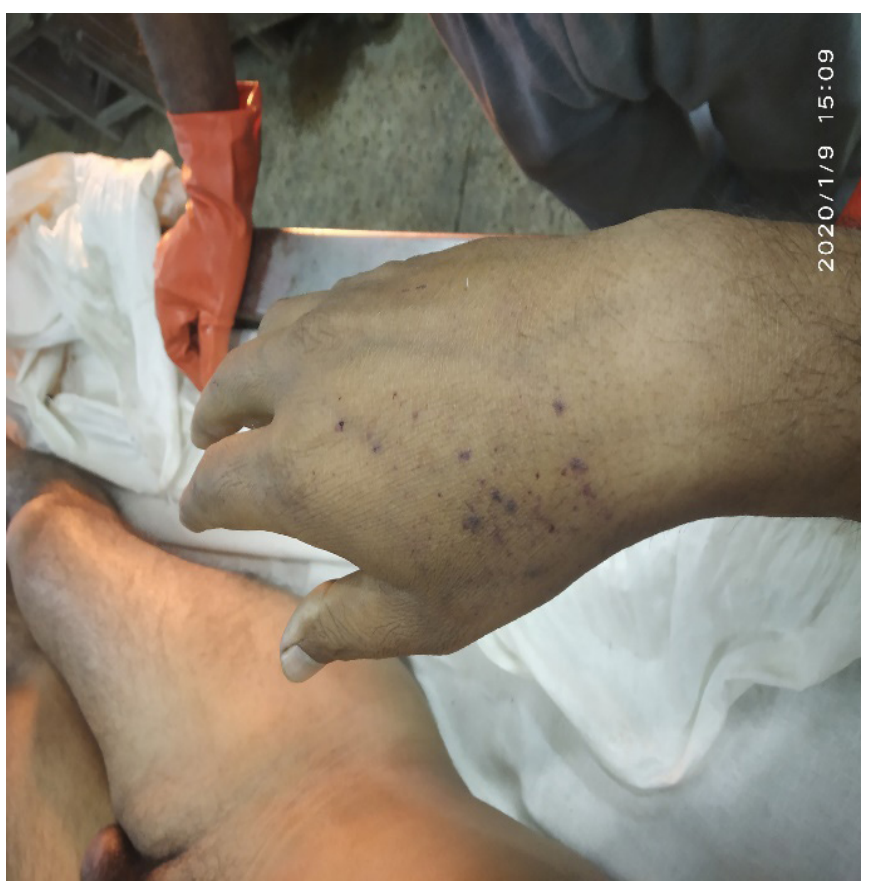

Figure 2: Tattooing on the dorsal aspect of hand

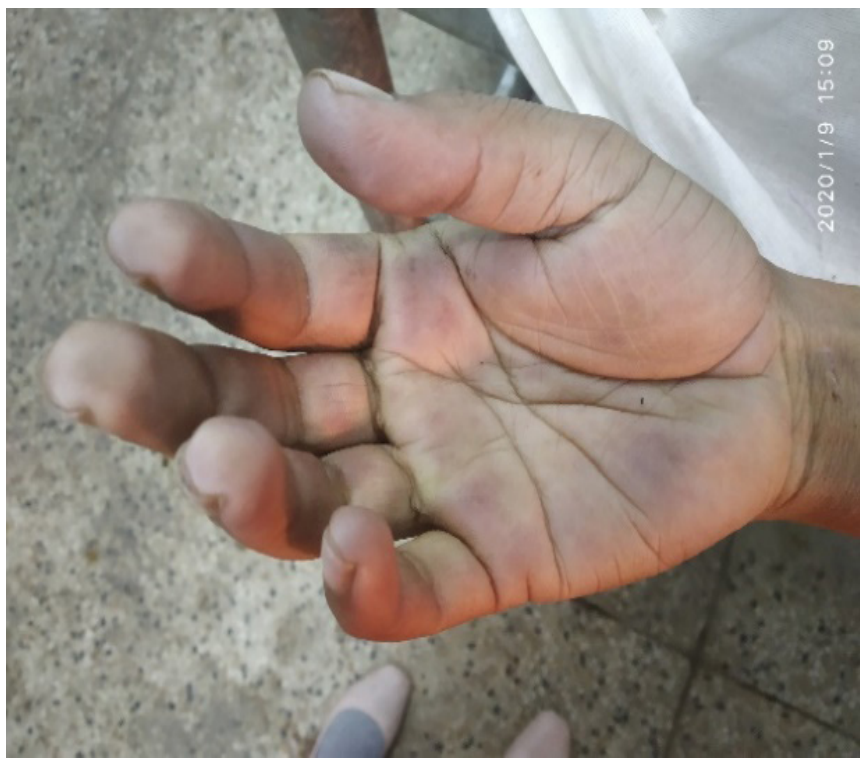

Figure 3: Presence of Black Powdery substance on the palm and fingers. 


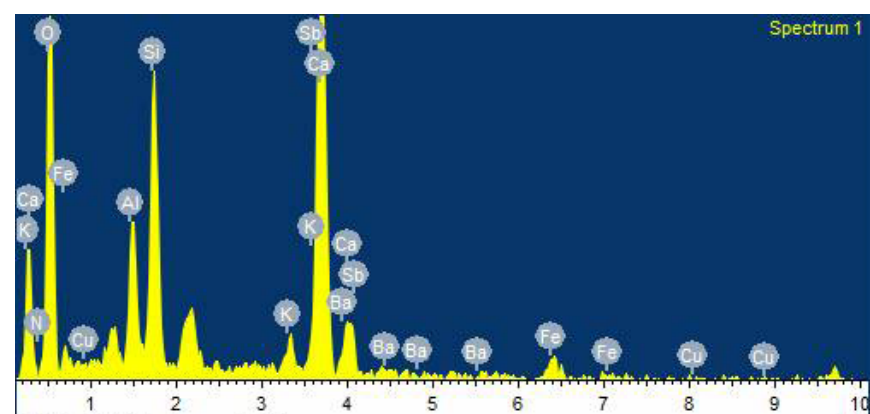

Full Scale 216 cts Cursor: 0.000

Figure 4: SEM-EDX Spectrum of GSR showing its elemental composition

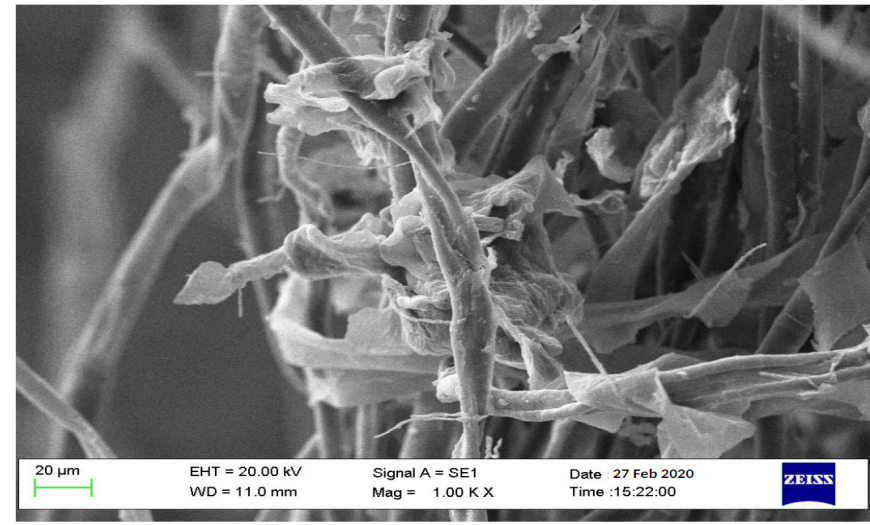

Figure 5: SEM image showing small diffused particles of GSR detected on the swab.

Due to the rupture of anterior cranial fossa in this shot i.e., contact shot, ectopic bruise in the form of a black eye or panda's eye is present and bleeding through both the nostrils.

On examination of the dorsal aspect of hand, unburnt gunpowder particles are present in the form of tattooing or peppering effect this is depicted in the Figure 3.

On the palmar aspect of the hand, GSR residues were present, and it was collected for SEM-EDXA by swabbing. The residues can be clearly seen in Figure 2.

\section{Internal Examination}

On opening, the skull dura matter was ruptured. Prior to skull and dura matter, blackening was present in sub-galeal regions and subperiosteal regions due to the blow-black phenomenon.

On further removing the dura matter, subarachnoid and subdural hemorrhage was present profusely over both the cerebral hemisphere.

The inner table of skull shows a bevelling effect with fracture of anterior cranial fossa with a dimension of the fracture is $1.2 \mathrm{~cm}$ in length and $0.7 \mathrm{~cm}$ in breadth. This anterior cranial fossa fracture internally is responsible for a black eye and bleeding through nostrils.

In this case, it is evident from the wound's position that it is one of the commonest sites of infliction of firearm entrance wound in suicidal cases.

The wound's nature is contact shot which is stellate shaped or cruciate shaped injury suffices the criteria of contact shot wound.

\section{Ballistic Findings}

No bullet was recovered. The bullet got exit from the occipital region of the skull. It had created an exit, which was smaller than the entry.

\section{Gunshot Residue Findings}

The samples were scanned for the image of gunshot residue, and EDXA was utilized for the determination of elemental composition.

\section{Detected Elements}

The GSR was subjected to SEM-EDX analysis for detection of its elemental composition. The elements detected from the sample consisted of nitrogen, oxygen, aluminum, silica, potassium, iron, copper, strontium, and barium. Figure 5 shows the SEM-EDX spectrum. Particles of 20-100 micrometers of small spherical, conical or rectangular and of various sizes were detected in the GSR spectrum image of the swab as shown in the Figure 4. GSR was mainly collected from front and back of the palm of the deceased. The elements analyzed in the image were mainly:

Oxygen, which is derived from barium nitrate and lead peroxide.These act as a propellant in the gunpowder. Its weight percentage is more than $50 \%$ of entire constituents of GSR detected by SEM-EDX.

Aluminum detected in the elemental analysis is used to stabilize the gunpowder, and it also acts as a source of energy for GSR. The nitrogen detected in the sample was derived from potassium nitrate, which is $75 \%$ of the total gunpowder.

Copper in the sample is derived from jacket of the bullet and the iron detected is from the metallic fowling present in gun barrel as it was in tight contact with the skin.

The three major components of GSR, antimony-leadbarium were detected in the spectrum produced during GSR analysis in various percentage i.e., antimony was $1.63 \%$ by weight, barium was $0.78 \%$ and lead was $0.04 \%$. The presence of spherical particles of $\mathrm{Sb}-\mathrm{Pb}-\mathrm{Ba}$ are the three main constituents of GSR. The presence of all these three in one spectrum confirms that GSR particles were present in the swab samples taken from the hand of the victim. This SEM-EDX test confirms the presence of GSR as it is the most sophisticated and sensitive test for the detection of GSR in present time. Hence it is inferred that along with post-mortem analysis, detection of GSR favors the manner of death to be suicidal.

\section{Discussion}

The distinction between suicidal, homicidal, and accidental firearm injuries is the most difficult as well as the most frequently asked question. Sometimes it is even impossible to point out. One of the crucial factors in it is the range of fire. A distant shot usually eliminates suicide unless any special circumstances are involved.

As per a study conducted in $2007-08,5 \%$ of the total firearm injuries were suicide. In India, where the preferred method of suicide is hanging and poisoning, these statistics indicate an increase in the trend of firearm suicides. Easy 
availability of unauthorized firearm is one of the prime cause of this increase.

The characteristic shape of the entry wound is an example of firm contact of firearm with the skin having a shallowly situated bone underneath. When a discharge from firearm occurs, the gases and other effects, including soot, unburnt, or partially burnt powder, penetrate the skin, in our case scalp. Still, the bone disrupts their entrance, further acting as a barrier and reverts it back. The large expanding gas's dome then splits the skin causing the eruptive appearance or cruciate shaped or stellate shaped wound. ${ }^{10}$ This effect of the formation of cruciate, stellate, or ragged laceration is also called the Blast effect. ${ }^{10}$ In case of contact shot, contrary to the normal finding of exit wound being larger than entry wound, exit wounds are smaller. This is due to elastic nature of the skin. ${ }^{11}$

Another factor which plays an important role in all suicidal infliction of injury is the accessibility of the body part on which the injury was inflicted. The vast majority of the shots are in the head and chest region. Among these the right temple area is preferred most frequently, followed by the floor of mouth and forehead. Forehead is the third most common site. ${ }^{12}$

One of the three most common cause of bruising in the eye lid, which is also known as the black eye, racoon eye or panda eye is the entering of blood in orbit from behind or above due to a crack in the walls of orbit, mostly due to fracture of floor of anterior cranial fossa. ${ }^{13}$ The fracture in our case was caused due to penetration of bullet through the anterior cranial fossa of the skull.

The presence of gunshot residue on hands also proves to be helpful when corroborative with circumstantial evidences. This GSR originates in parts from the blowback associated with blast effect as well as from the frame work of the firearm used. In India use of desi kattas or improvised firearm weapons is also common. These being cheap and easily available are easy to keep in possession than a licenced firearm. They are not built according to standard firearm manufacturing protocols. Presence of tattooing on the hand of the victim is a result of back fire from this type of substandard but lethal weapon. Laboratory experiments involving handguns have shown that the index finger, thumb, and connecting web of the shooting hand are most likely to be positive for GSR. ${ }^{14}$ Amongst several techniques which are present for the evaluation of GSR, SEM-EDXA is considered to be the best for the analysis of characteristic trio of elementsPb-Sb-Ba. The scanning electron microscope uses a focused beam of high-energy electrons to generate a variety of signals at the surface of solid specimens. The signals that derive from electron-sample interactions reveal information about the sample including externalappearance. EDX, an accessory device, has increased the utility of the instrument many times by providing elemental composition. ${ }^{15}$ In suicides with handguns, primer residues on the palm may be due to cradling the gun with hand at the time of firing. In regard to collection of GSR, a study by DeGaetano and Harrison presented at the conference revealed that GSR collection from the hands of suicide victims at the scene was positive $92 \%$ of the time whereas GSR collected from the hands of suicide victims at the morgue was positive $76 \%$ of time. ${ }^{12}$

\section{Conclusion}

Suicide by means of firearm is increasing at an alarming rate. Possession of illegal firearms is one of the leading cause. Easy availability of this lethal weapon leads to suicide when a person is in rage or sometimes it is just an impulse. Most of the men who commit suicide are young aged men who had their whole life in front of them. Men who were capable of contributing to society for good. Strict laws should be made and a complete ban on manufacture and sale of such illegal firearms should be imposed. Heavy punishment should be foisted on people who do not abide by these laws.

\section{Ethical Considerations}

\section{Compilation with Ethical Guidelines}

The present study was approved by Institutional Ethical Committee of the Institute of Medical Sciences, Banaras Hindu University. As this case report was prepared from medico-legal autopsy performed at our departmental mortuary, we have statutory right to conduct post- mortem examination and to publish the findings.

\section{Funding}

The present study was funded by University Grants Commission.

\section{Author's Contribution}

Both the authors have contributed explicitly in preparation of this paper.

\section{ACKNowledgement}

Authors would like to thank Faculty and Staff of Department of forensic medicine, IMS, BHU for their valuable support in preparation of this case report. Special thanks to print and electronic media for providing us with immense resource materials in preparation of this article.

\section{REFRENCES}

1. India has the highest suicide rate in South-East Asia: WHO [Internet]. [cited $2020 \mathrm{Aug}$ 26]. Available from: https://www. downtoearth.org.in/news/health/india-has-the-highest-suiciderate-in-south-east-asia-who-66625

2. Suicide in India - Wikipedia [Internet]. [cited 2020 Aug 26]. Available from: https://en.wikipedia.org/wiki/Suicide_in_India

3. Suicide [Internet]. [cited 2020 Aug 26]. Available from: https:// www.who.int/news-room/fact-sheets/detail/suicide

4. Section 309 in The Indian Penal Code [Internet]. [cited 2020 Dec 5]. Available from: https://indiankanoon.org/doc/1501595/

5. Section 309 of the Indian Penal Code. In: Wikipedia [Internet]. 2020 [cited 2020 Aug 26]. Available from: https://en.wikipedia. org/w/index.php?title=Section_309_of_the_Indian_Penal_ Code\&oldid $=988181498$ 
6. Kumar S, Verma AK, Bhattacharya S, Rathore S. Trends in rates and methods of suicide in India. Egypt J Forensic Sci. 2013;3(3):75-80.

7. Kohli A, Aggarwal NK. Firearm fatalities in Delhi, India. Leg Med. 2006;8(5):264-268.

8. Reddy MS. Suicide incidence and epidemiology. Indian J Psychol Med. 2010;32(2):77.

9. Khan I, Shakeel M, Usmani JA, Hasan SA. Emerging trends of intentional firearm injuries in Northern India: a study. J Clin Diagn Res JCDR. 2016;10(10):HC01.

10. Vij K. Textbook of forensic medicine and toxicology: principles and practice. India: Elsevier; 2014.
11. Biswas G. Review of Forensic Medicine \& Toxicology. 3rd edition. Jaypee Brothers Medical Publishers; 2015.

12. DiMaio J. Practical aspects of firearms, ballistics and forensic techniques. 3rd edition. CRC Press; 2016.

13. Modi P. Textbook of Medical Jurisprudence and Toxicology. 25th ed. LexisNexis; 2016.

14. Spitz U, Fisher S. Medico-legal investigation of death: guidelines for the application of pathology to crime investigation. 1st ed. Charles C Thomas Publisher; 1972.

15. Sharma B. Firearms in Criminal Investigation and Trials. 5th ed. Universal Law Publications; 2017. 